\title{
Diversity Management Using The Diversimilarity Paradigm: A Case Study Of A Major Mid-West Food Retailing And Distribution Corporation
}

Joseph Ofori-Dankwa, (E-mail: oforidan@svsu.edu), Saginaw Valley State University Surender Reddy, (E-mail: reddy@svsu.edu), Saginaw Valley State University

\begin{abstract}
The diversimilarity approach emphasizes managing a diverse work force through an appreciation of cultural and demographic similarities and differences that may stem from such characteristics as gender, age, physical ability, ethnicity, and religion. This article highlights how a major mid western food distribution corporation with 4000 plus employees applies the diversimilarity paradigm.
\end{abstract}

\section{INTRODUCTION}

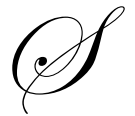

ince the turn of the century, major U.S. corporations and several managers have managed diversity with the similarity approach, in keeping with the idea of assimilation. According to Thomas (1991, p.7),

"newcomers are expected to adapt so that they 'fit.' The burden of making the change falls to them." In other words, people from diverse backgrounds are expected to conform to the Eurocentric values of the dominant white male culture (Cox, 1993).

Organizations and individual managers operating under the similarity paradigm are likely to attract and hire people whose cultural values or demographic characteristics are similar to those of top management. The advantage is a high level of compatibility in the workplace. There is also likely to be a powerful "dissimilarity-attrition effect," however, which means that people who do not "fit" are fired or leave the organization (Schneider 1987). The disadvantage is the lack of diversity and new ideas, and this may hamper an organization's ability to cope with change.

More recently, organizations and managers have begun to use the diversity paradigm. For example, the flexmanagement model is based on individualizing the way we manage-accommodate differences and on providing choices wherever possible (Jamieson and O'Mara 1991, p. 11). The focus is on individual and group cultural and demographic differences. One advantage is that new ideas and ways of operating are likely to emerge, which can make an organization more flexible and adaptable (Nemeth 1986). For example, it can understand and effectively market products and services to minority segments (Cox, 1993; Cox \& Blake, 1991). In addition, the diversity paradigm results in more minorities being hired. Yet, by focusing primarily on differences it, paradoxically, may become more difficult to value differences. The diversity approach may lead to increased inter-ethnic tensions in the workplace (Mobley and Payne 1992, Thomas 1994), and absenteeism, turnover, and a decrease in organizational commitment (Tsui et al. 1992, Jackson et al. 1991).

\section{THE DIVERSIMILARITY APPROACH TO DIVERSITY MANAGEMENT}

In contrast to using a primarily diversity or similarity approach, some individuals and organizations use the diversimilarity paradigm (Loden \& Rosener, 1991). Several studies both empirically and theoretically suggest that the 
nature of an individual's workforce management paradigm (e.g. whether assimilation, diversity or diversimilarity) will have powerful and profound implications on subsequent strategic actions of a wide range of individuals such as researchers (Ofori-Dankwa \& Ricks, 2000; Ofori-Dankwa \& Tierman, 2002), professors ( Ofori-Dankwa \& Lane, 2000) and managers in organizations (Ofori-Dankwa \& Julian, 2002a). Subsequently, organizations using the diversimilarity approach will tend to actively recruit minorities and also develop specific programs to emphasize the value of differences and similarities among employees (Loden \& Rosener, 1991; Ofori-Dankwa \& Bonner 1998; Ofori-Dankwa, Sype \& Arora, 1999). Programs may include sensitivity training to foster the appreciation of commonalities and cultural differences. Training also can help managers and employees distinguish between similation and assimilation (Ofori-Dankwa 1996, Ofori-Dankwa and Bonner 1998). The former involves identifying and appreciating similarities found in individuals from different backgrounds, whereas the latter stresses adjusting to the dominant culture.

The diversimilarity approach is based on the competing values model, which takes a both/and perspective rather than an either/or perspective (Quinn 1988). Loden and Rosener (1991, p. 145) maintain that "the diversity paradox or the idea that people are different and similar is an important part of educational efforts to support diversity." Thus, policies that promote the awareness and appreciation of diversity as well as commonalities are not mutually exclusive. Furthermore, one needs to understand institutionalized differences. For example, it is as important to value cultural differences as it is to recognize the continued systemic discrimination that minorities may face. Finally, the idea of similarity is no less important that is, the basic humanity and needs shared by all people, or the basic spiritual urges expressed in different religions. The diversimilarity approach will therefore entail a systematic analysis and development of programs and policies in an organization that will simultaneously focus on demographic and cultural differences and similarities. Most recently, diversity and similarity curves have been proposed as a way to more effectively capture the inherent paradox associated with the simultaneous consideration of both differences and similarities within an organizational context (Ofori-Dankwa \& Julian, 2002b; Ofori-Dankwa \& Julian, 2004).

The diversimilarity concept therefore seeks to build on the positive aspects of the similarity and diversity paradigms ( Ofori-Dankwa \& Julian, 2002a). A focus on employee commonalities should decrease tension and conflict, increase organizational commitment, and reduce turnover and absenteeism. Paying attention to differences can result in the generation of new ideas and an organization that is flexible, adaptable, and customer oriented. Nevertheless, diversimilarity has limitations. First, due to the long history and entrenched influence of assimilation, some organizations are reluctant to shift focus. Second, the approach is inherently complex because it simultaneously considers similarities and differences (Ofori-Dankwa \& Julian, 2002a; Ofori-Dankwa \& Julian, 2004). Indeed as pointed out by Quinn (1988), managers and organizations are not comfortable with paradox and tend to prefer an either/or framework.

\section{A CASE STUDY OF HOW A MAJOR MID-WESTERN FOOD RETAILING AND DISTRIBUTION CORPORATION USES THE DIVERSIMILARITY PARADIGM}

The first author interviewed top personnel of a major Mid Western food retailing and distribution corporation to obtain information for this case study. In particular the first author was able to meet with and spend substantial time interviewing the human resource director and also the current CEO and chairperson of the corporation in 1998 and 1999.

The corporation begun in the early 1940s when its founder, the father of the current CEO and chairperson of the corporation's board, opened a food retailing store in a mid size city in Michigan. The current chairman of the board assumed leadership of this corporation in the mid seventies after the death of his father. His personal views are important in understanding why the company adopted the diversimilarity approach. He had served in the Armed Forces, where he met and befriended several people from diverse ethnic backgrounds. The negative experiences of his friends led him to conclude that although this nation was founded on the ideal of equality, that ideal is not being realized because of discrimination and racism. His subsequent readings of such authors as Cornell West (1993) and Nathan Rutstein $(1993 ; 1997)$ convinced him that unless this is acknowledged, individuals cannot fully understand one another. 
The chairperson grappled with and identified several paradoxes. For example, individuals are different, yet they have commonalities and share the human spirit. All human beings have prejudices, yet people of color face institutionalized discrimination. It is important not only to acknowledge the spiritual instinct of human beings but also to respect their different beliefs. Thus, his management philosophy largely reflects the core principles of diversimilarity.

- We need to recognize and respect the basic humanity of everyone as well as the uniqueness of each individual.

- The CEO has to be the primary change agent if the organization is to value diversity. Change must start at the very top. The CEO must communicate verbally and in writing to all associates in the organization the need for and value of diversity.

- $\quad$ There is a need to articulate that racism and discrimination exist and prevent ethnic minorities from reaching their fullest potential. Paradoxically, discrimination is also harmful to the majority population.

- $\quad$ The CEO must walk the talk. The CEO and top management team must support the diversimilarity approach one hundred percent.

\section{Internal Corporate Programs}

Clearly, the Chairman of the Board's strong interest in racial diversity and his philosophy of trying to ameliorate the negative effects of racism has substantially shaped the corporation's current approach to diversity management. Every store-level associate and manager must attend a two-hour Living with Diversity workshop. The stated goal of this worshop is to heighten the awareness of how cultural diversity affects "each of us personally and professionally. As we identify the differences and similarities that exist among all people, we will better understand how to value cultural diversity." The Living with Diversity workshop uses skilled facilitators to help participants identify, and explore the opportunities and challenges associated with workforce diversity. In particular, it focuses on increasing the cultural sensitivities of workshop participants to the potential challenges of minority group members when working in a majority culture and the potential challenges majority group members as they interact with minority co-workers. Finally, the session facilitator generates participant discussions as to how to more effectively address challenges that participants may encounter as they work with co-workers from diverse demographic and cultural backgrounds. Most of the associates of this corporation including the entire management team have participated in the Living with Diversity workshop.

A three hour advanced seminar, "Fish Out of Water", is optional, but associates are strongly encouraged to attend. Its stated goal is "to demonstrate the process of learning how to value diversity and community within a customer/associate oriented company." One learning objective is to understand that "the challenge of valuing and managing diversity is relating to a person as a human being, a member of cultures and a unique individual." About 400 associates participate in these annually. The "Fish Out of Water" seminar is mandatory for management level associates.

The corporation also undertakes regular surveys of employees to ascertain the organizational climate. These anonymous and confidential surveys reveal a culture that values diversity. The workshops are also evaluated, and the ratings have been consistently positive. It should be noted that attendance at the two workshops counts toward the promotion of associates, which shows the importance the management team places on diversity. Other factors are taken into account, of course, such as length of time with the corporation and job performance.

In addition, the corporation offers Institute for the Healing of Racism sessions to employee and managers. Institute for the Healing of Racism sessions are structured discussions and dialogues on racism and prejudices and how co-workers from different ethnic backgrounds can begin to build trust and understanding. In sessions, which extend over sixteen weeks, a group of twenty associates will meet every other week (8 sessions) for one and one-half hours. The sessions are led by skilled facilitators who create a safe and respectful atmosphere for the sharing of experiences and perceptions about prejudices and racism, learning from the shared experiences and assisting individuals in gaining "a deeper understanding and a renewed hope for the future of humanity". The sessions enable participants from all 
races and ethnic backgrounds to speak candidly about their experiences with racism and to candidly confront individual prejudices. The assumption is that if a diverse group of well-intentioned people can dialog honestly with one another, then they will cease to be foes and become allies. They will recognize their common humanity, which will make it easier for them to appreciate their distinctiveness and individuality. Associates at the corporation must first attend the two other workshops before participating in the Institute for Healing of Racism. The Institute for the Healing of Racism has so far provided learning to more than 500 corporate associates since it was developed in 1992

The corporations' investment is considerable as employees and managers are paid for attending the workshops. The corporation is also building an internal pool of facilitators, who not only have completed the workshops and institute but also have at least ten hours of additional training. This includes instruction on facilitation, workshop observation, supervised co-facilitation, and a feedback evaluation.

There is an aggressive effort by the corporation to recruit minority employees, who currently account for 10 percent of the work force. This is especially remarkable in view of the fact that some communities where the corporation has stores have a relatively small minority population. The voluntary goal is to consistently increase the number of minority employees at the corporation. In the general hiring process, the corporation specifically seeks people who are sensitive to the value of diversity.

The corporation is also aware of the cost of racism and poor race relations in terms of law suits as well as employee absenteeism and turnover. It also recognizes the benefits of diversity in terms of customer satisfaction and loyalty. The CEO and top management are therefore totally committed to this approach. They believe it is the right thing to do and is also very good for business. To maintain this focus, principles and values statements involving the importance of respect, dignity, and caring are posted around the organization.

\section{Reaching The Wider Community}

The corporation is increasingly recognized as a leader in the effective management of diversity and currently serves as a diversity resource center for several organizations, such as the Parent Teacher Associations and local hospitals, when they call seeking assistance and information in diversity related issues. These consultations are free.

In addition, the corporation works with various religious groups. The company's philosophy is to respect all religions. A non coercive effort is made to spread increased awareness of this notion among employees. The corporation also is developing partnerships with schools, churches, and other groups to help foster appreciation of diversity and commonalities. For example, the corporation has partnered with area community churches in presenting more than eight Institute for the Healing of Racism sessions. The corporation also has helped organize and facilitate faith-based workshops as well as ecumenical services among Catholic, Episcopal, and Bahai groups. The corporation is the only non-faith organization on the steering committee of faith-based organizations helping in the implementation of Institute for Healing of Racisms in various religious and spiritual groups.

The corporation also has partnered with the regional Chamber of Commerce to provide an Institute for the Healing of Racism workshop for approximately thirty CEOs and top executives of major corporations and organizations in the area. The corporation has helped the region's chamber of commerce to form cultural diversity council.

\section{Bottom Line Results}

The corporation has achieved some very positive results with the diversimilarity approach. It consistently enjoys a high level of customer loyalty. It is an acknowledged leader in customer satisfaction in the supermarket industry and has received numerous better business awards. The corporation continues to be very profitable and has grown steadily. There are now 21 stores in the Mid-western region with over 4,100 associates. 
The corporation's annual turnover is about forty-five to fifty percent, well below the industry rate of almost 100 percent. Annual surveys of job satisfaction and organizational commitment among associates have consistently been excellent. The company is an acknowledged industry leader in terms of race relations with its associates. The corporation's top personnel are often asked to speak about its diversity management approach and methods at various conferences, such as the 1997 meeting of the Food Marketing Institute. In addition, the chairperson of the board has been widely recognized in the community and given several awards including the community's visionary award.

\section{CONCLUSION}

Given the changes in U.S. demographics, the ability to manage a diverse work force is crucial for the bottom line. Organizations that use the similarity paradigm may not have diversity in their work force, which means they cannot benefit from the advantages it offers. Organizations that use the diversity paradigm may encounter the limitations described earlier.

As the case study of this corporation illustrates, a policy of valuing cultural differences, reducing systemic minority disadvantages, and appreciating human commonalities promotes not only good interpersonal relations among employees but also customer satisfaction. These will translate into increased sales, growth, and profits. The philosophy of the Chairman of the Board, and the top management team is best reflected in the corporations stated diversity commitment: "It is time to embrace our founding ideals of equality, opportunity, and justice... (and) actively working towards the healing racism and celebrating diversity"

\section{REFERENCES}

1. Cox, T (1993) Cultural Diversity in Organizations: Theory, Research \& Practice, Berrett-Koehler Publishers: San Francisco.

2. Cox, T.H. \& S. Blake (1991) Managing Cultural Diversity: Implications for Organizational Competitiveness, Academy of Management Executive, 5:3, 45 - 56.

3. Jackson, S., J. F. Brett, V. I. Sessa, D. M. Cooper, J. A. Julin, \& K. Peyronnin (1991). Some Differences Make a Difference: Individual Dissimilarity and Group Heterogeneity as Correlates of Recruitment, Promotion, and Turnover, Journal of Applied Psychology 76(5), 675-89.

4. Jamieson, D. \& J. O'Mara (1991). Managing Workforce 2000: Gaining the Diversity Advantage (San Francisco, CA: Jossey-Bass).

5. Loden, M. \& J. B. Rosener (1991). Workforce America, Managing Employee Diversity as a Vital Resource (Homewood, IL: Irwin).

6. Mobley, M. \& T. Payne (1992). Backlash! The Challenge to Diversity Training, Training and Development (December), 45 - 52.

7. Nemeth, C. J. (1986). Differential Contributions of Majority and Minority Influence, Psychological Review $93(1), 23-32$.

8. Ofori-Dankwa, J \& A. Tierman (2002) The Effect of Researcher Focus in Interpretation of Diversity Data, Journal of Social Psychology, 142:3, 277 - 293.

9. Ofori-Dankwa, J \& D. A. Ricks (2000) Research Emphasis on Cultural Differences and or Similarities: Are We Asking the Right Questions? Journal of International Management, 6:2, 173 - 186.

10. Ofori-Dankwa, J \& R. Lane (2000) Four Approaches to Cultural Diversity: Implications for Teaching in Institutions of Higher Education, Teaching in Higher Education, 5:4, 493-500.

11. Ofori-Dankwa, J \& S. Julian (2002) a The Diversimilarity Approach to Diversity Management: Strategies for Managers Chapter in C. Harvey \& M.J. Allard (eds), Understanding and Managing Diversity: Readings, Cases and Exercises, $2^{\text {nd }}$ Edition, Prentice Hall, $84-88$.

12. Ofori-Dankwa, J \& S. Julian (2002) b Toward Diversity and Similarity Curves: Implications for Theory, Research and Practice, Human Relations, 55:2, 119 - 224.

13. Ofori-Dankwa, J. \& R. Bonner (1998). A New Look at Corporate Diversity Training and management: From Affirming Diversity to Affirming DiverSimilarity Multi-Cultural Review, 7:3, 40 - 43, 54. 
14. Ofori-Dankwa, J. \& S. Julian (2004) Conceptualizing Social Science Paradoxes using Diversity and Similarity Curves Model: Illustrating the Work/Play and Novelty/Continuity Paradoxes, Human Relations, $57: 11,1449-1477$.

15. Ofori-Dankwa, J. (1996). From Diversity to DiverSimilarity: Shifting Paradigms to Match Global and National Realities. In K. Roberts and M. Wilson, eds., Policy Choices, NAFTA and Michigan's Future (East Lansing: Michigan State University Press). Pp. 271-87.

16. Ofori-Dankwa, J., G. Sype, \& S. Arora (1999) A Typology and Integrated Model of the Primary Determinant and Effects of Cultural Diversity Paradigms, Journal of Contemporary Business Issues, 6:2, 58 - 67.

17. Quinn, R. (1988). Beyond Rational Management: Mastering the Paradoxes and Competing Demands of High Performance (San Francisco, CA: Jossey-Bass).

18. Rutstein, N (1993) Healing Racism in America: A Prescription for the Disease (Springfield, MA; Whitcomb Publishing).

19. Rutstein, N (1997) Racism: Unraveling the Fear (Washington, DC: The Global Classroom).

20. Schneider, B. (1987). The People Make the Place, Personnel Psychology 40, 437-53.

21. Thomas, R., Jr. (1991). Beyond Race and Gender: Unleashing the Power of Your Total Workforce by Managing Diversity (New York: AMACOM).

22. Thomas, V.C. (1994). The Downside of Diversity, Training and Development (January), 60.

23. Tsui, A. S., T. D. Egan, \& C. A. O'Reilly III (1992). Being Different: Relational Demography and Organizational Attachment, Administrative Science Quarterly 37, 549-79.

24. West, C (1993) Race Matters, (Boston, MA: Beacon Press).

\section{NOTES}

